\title{
GESTÃO AMBIENTAL NO BRASIL: O CAMINHO PARA A SUSTENTABILIDADE
}

\author{
Cláudia de Oliveira Gonçalves Nogueira ${ }^{1}$
}

Sarita Soraia de Alcântara Laudares ${ }^{2}$

\section{Luís Antônio Coimbra Borges ${ }^{3}$}

RESUMO: $O$ acelerado ritmo de industrialização e consequente concentração de contingentes populacionais em áreas urbanas, principalmente na década de 1960, passaram a provocar profundos impactos no meio ambiente. O agravamento destes no Brasil tornou-se notório em áreas onde a atividade industrial era mais intensa como Cubatão, Volta Redonda, ABC Paulista, entre outras metrópoles do país, o que promoveu a atividade industrial a fator determinante nas transformações ocorridas. As pesquisas que tratam dos impactos advindos da Gestão Ambiental no Brasil, são de suma importância para que se possa fazer uma análise da evolução das políticas ambientais e assim, expor os pontos a serem melhorados e sucessos já alcançados. Esta revisão foi elaborada a partir da análise da evolução da gestão ambiental brasileira, destacando alguns conceitos e abordagens conflituosos. Como resultado, é indiscutível que houve avanços institucionais e legais, mas estes são ainda insuficientes para instituir no Brasil um modelo sustentável de desenvolvimento, com aspectos de distribuição em que viabiliza a equidade dos benefícios materiais e sociais oriundos do crescimento econômico. Com relação à doutrina ambiental brasileira, mesmo sendo a mais bem idealizada do mundo, ainda se observa a carência de vontade política para aplicá-la, além de normas mais coerentes com a capacidade de fiscalização que, aliás, são quase que nulas diante de Leis tão complexas e contraditórias.

Palavras-chave: Meio ambiente. Recursos naturais. Gerenciamento ambiental.

\footnotetext{
'Discente de Doutorado em Ciências Florestais, Universidade Federal de Lavras; Docente do Centro Universitário de Formiga - UNIFOR MG. E-mail: claudiaogn@gmail.com

${ }^{2}$ Discente de Mestrado em Ciências Florestais, Universidade Federal de Lavras. E-mail: saritalaudares@gmail.com.

3Engenheiro Florestal, Universidade Federal de Lavras, Professor Adjunto. E-mail: luis.borges@dcf.ufla.br.
} 


\section{INTRODUÇÃO}

As transformações ambientais causadas pela sociedade são tão antigas quanto à própria existência humana. A relação homem-natureza sempre esteve muito ligada à utilização dos recursos naturais fazendo com que, o convívio com o meio ambiente marcasse a própria capacidade de sobrevivência da espécie, na medida em que dependia dos produtos coletados e da caça. As pesquisas que tratam dos impactos advindos da evolução da Gestão Ambiental no Brasil, são de grande importância para que se possa fazer uma análise da evolução das políticas ambientais. Segundo Coelho (2003), é a partir da década de 1930, com um Estado centralizador, que se nota a emergente regularização das políticas ambientais no país.

A Gestão Ambiental é reconhecida como o conjunto de atividades relacionadas ao planejamento e alocação de recursos, objetivando efeitos positivos sobre o meio ambiente, quer reduzindo, eliminando ou prevenindo danos ambientais. De outra maneira, é a conciliação do uso dos recursos naturais com a proteção ambiental, visando à sustentabilidade e, portanto, a produtividade em longo prazo. O gerenciamento ambiental também envolve a escolha coerente dos serviços públicos oferecidos à comunidade, criação de leis, normas e a penalização para quem causa algum tipo de dano ao ambiente. Além disso, entende as diferentes relações entre a sociedade e a natureza, sendo mediador de possíveis conflitos de intenções. Contudo, a análise da Gestão Ambiental como reguladora dos processos econômicos através de estimativas de impactos ambientais ou instrumentos econômicos para a valorização dos recursos naturais é muito simplista, já que não há como estipular um valor real da natureza.

A responsabilidade empresarial quanto ao meio ambiente deixou de ter apenas característica compulsória para transformar-se em atitude voluntária, superando as próprias expectativas da sociedade. O comprometimento das empresas com a questão ambiental acompanha o processo de globalização das relações econômicas, impulsionando a partir da década de 1970. Faz parte da construção de uma ética global, partindo das sociedades mais prósperas, pois os fenômenos de poluição transcedem as fronteiras nacionais e afetam grandes extensões regionais e mesmo o Planeta como um todo. 


\section{CONCEITOS AMBIENTAIS BÁSICOS}

Todas as ações humanas alteram o ambiente natural e a civilização atual não seria possível sem a ocupação e uso intensivo dos mesmos, mas há risco de seu esgotamento ou de que seja alterado de tal forma que não se possa mais utilizá-lo. O objetivo dos cuidados com o ambiente deve ser de conservação dos seus recursos bióticos e abióticos, procurando evitar que os mesmos se esgotem ou que sejam alterados de forma a se tornarem inúteis ou prejudiciais. Os recursos naturais são essenciais à civilização humana e podem ser renováveis e não renováveis. Um ambiente saudável para o ser humano é aquele que permite que viva com saúde e recursos suficientes para sua sobrevivência.

A garantia de que os recursos naturais se mantenham com a qualidade e quantidade dos níveis originais ao longo do tempo e permita que as futuras gerações encontrem as mesmas condições para sua sobrevivência que a atual, denomina-se sustentabilidade. Isso é entendido como premissa básica a tentativa permanente de alcançá-la e a Constituição da República Federativa do Brasil, em seu Artigo 225, determina que todos têm direito a um ambiente ecologicamente equilibrado, Brasil, 1988.

De um modo geral, a Gestão Ambiental é consequência natural da evolução do pensamento da humanidade em relação à utilização dos recursos naturais, é a união de técnicas, conhecimentos, tanto por parte da sociedade, bem como do setor empresarial, em busca de soluções e alternativas para manter o equilíbrio ambiental, reduzindo ou recuperando a degradação do meio natural (ALCANTARA et al., 2002).

Quintas, (2006 p30), define gestão ambiental como processo de mediação de interesses e conflitos (potenciais ou explícitos) entre atores sociais que agem sobre os meios físico-natural e construído, objetivando garantir o direito ao meio ambiente ecologicamente equilibrado, conforme determina a constituição. 


\section{Gestão AMBIENTAL PÚBlicA E PRIVAdA E O DESENVOLVIMENTO SUSTENTÁVEL NO BRASIL}

O Brasil, a partir da década de 1950, vem sofrendo grande transformação devido ao crescimento demográfico e da modernização de suas bases de desenvolvimento. De um estágio de economia predominantemente exportadora de produtos agrícolas passou a um estágio de industrialização considerável, com um índice de crescimento de 9,3\% a.a. da população industrial no período de 1970 a 1990, segundo Vianna e Veronese, 1992.

No início da década de 1970 até os dias atuais, pode-se observar um crescente e contínuo de institucionalização de políticas e práticas de gestão ambiental manifestado na criação de agências ambientais governamentais, no marco legal que normatiza a gestão dos problemas ambientais no país, no debate teórico- político que fundamenta e legitima a regulação da questão ambiental e na difusão de informações sobre a crise ambiental. Lima (2011), refletindo acerca do assunto conclui que houve avanços na política ambiental brasileira, contudo, de um modo contraditório e incapaz de superar a crescente degradação ambiental e os conflitos econômicos e políticos decorrentes da expansão capitalista no país.

O acelerado ritmo de industrialização e consequente concentração de contingentes populacionais em áreas urbanas, observado principalmente na década de 1960, passaram a provocar profundos impactos no meio ambiente. $\mathrm{O}$ agravamento da questão ambiental no Brasil começou a ser sentido em áreas onde a atividade industrial era mais intensa como Cubatão, Volta Redonda, ABC Paulista, e em outras grandes metrópoles brasileiras, o que promoveu a atividade industrial a fator determinante nas transformações ambientais ocorridas (NOGUEIRA, 2009).

A Gestão Ambiental no Brasil tem bases formuladas no processo de redemocratização do país na década de 1980 , contudo, poucos conceitos levavam em conta o sujeito social responsável pela gestão: o poder público. A própria instituição de políticas para o meio ambiente nasceu do poder tecnocrata, não do intercâmbio com a sociedade. Da década de 1930 até 1987 constata-se um forte intervencionismo do Estado e a partir de 1988, com o processo de redemocratização do início da década de 1980, as 
decisões tornam-se, teoricamente, mais 'abertas à sociedade', assim como há uma grande disseminação da noção de desenvolvimento sustentável (BOEIRA, 2003).

O conceito de desenvolvimento sustentável surge formalmente no bojo do Relatório Bruntland. De acordo com Mota (1998), este documento, realizado pela Comissão Mundial sobre Meio Ambiente e Desenvolvimento das Nações Unidas, introduz definitivamente a idéia de que o desenvolvimento econômico de hoje deve se realizar sem comprometer o desenvolvimento econômico das gerações futuras. Isto é, o desenvolvimento deve ser sustentável, o que pode parecer um conceito redundante ou pouco original, e que na verdade, traduz uma nova qualificação para os esforços de desenvolvimento com significativas simplificações econômicas e políticas.

A causa ambiental dos anos 1980 e 1990 atravessa fronteiras. A questão principal agora não se restringe à qualidade ambiental de um território. Aliás, esta perde ênfase em favor das questões ditas globais. Conforme esclarece o subtítulo do Relatório Bruntland, trata-se agora do "nosso futuro comum". A partir da definição de desenvolvimento sustentável pelo Relatório Brundtland, em 1987, é possível perceber que tal conceito não diz respeito apenas ao impacto da atividade econômica no meio ambiente. Desenvolvimento sustentável se refere, principalmente, às consequências dessa relação na qualidade de vida e no bem-estar da sociedade, tanto presente quanto futura (NASCIMENTO, 2010).

Desde o princípio, os órgãos públicos de meio ambiente no país têm sido formados numa estrutura de poder que os torna isolados dos outros órgãos, já que existe uma articulação interinstitucional vertical entre instâncias municipais, estaduais e nacionais e uma articulação horizontal entre as instâncias, a sociedade e o empresariado. Tais arranjos são ratificados pelo pequeno número de municípios que dispõem de órgãos ambientais com a devida especialização, estando a maioria restritos às políticas estaduais ou federais, impedindo que haja somente um complemento das instâncias distantes nas ações locais.

Os obstáculos à viabilização da emancipação política da sociedade para a participação na Gestão Ambiental são, dentre outros, a oposição do poder público e das elites em abrir mão do espaço que foi apropriado e o assistencialismo do governo. Não havendo participação da sociedade, as deliberações técnicas tornam-se afastadas da realidade local. Portanto, a consideração das diferenças nas sociedades, a defesa do 
meio ambiente como riqueza realmente coletiva e o fortalecimento das associações civis são atitudes necessárias para uma efetiva participação popular (LAYRARGUES, 2000).

A Constituição de 1988 afirma que o meio ambiente é um bem público, não podendo ser suscetível de apropriação privada.

Após a Conferência de Estocolmo em 1972, o processo de institucionalização de políticas e da gestão ambiental no Brasil experimentou avanços consideráveis, sobretudo nos aspectos institucionais e legais, na tendência à descentralização política no sentido do deslocamento de atribuições e de poderes para os níveis estaduais e municipais e também no sentido do compartilhamento de aspectos da gestão ambiental com entidades da sociedade civil e do setor privado e, por último, na construção e no fortalecimento da noção de desenvolvimento sustentável como recurso político na negociação dos conflitos que emergem da articulação entre o desenvolvimento e o ambiente (LIMA, 2011).

Cunha e Coelho (2008), por exemplo, analisando a emergência do paradigma do desenvolvimento sustentável, constatam uma disputa interna ao debate entre visões filosóficas contrastantes e a constituição de uma concepção hegemônica de desenvolvimento sustentável de caráter instrumental. Os autores identificam, por um lado, uma visão ecocêntrica fundada em uma compreensão complexa do planeta Terra e na necessidade de mudanças radicais dos padrões ético e político capazes de transformar a base produtiva da sociedade ocidental. Caracterizam, por outro lado, a abordagem instrumental como aquela que defende a conservação por seu valor econômico, o mercado e a gestão dos recursos como instrumentos eficientes de promoção do desenvolvimento e a ideologia do progresso como fundamento filosófico da sociedade desejada.

A percepção geral que fica do debate acima é a de que o processo de institucionalização das políticas ambientais no Brasil avançou relativamente; de uma forma tortuosa, vacilante e contraditória. Suas motivações, objetivos e instrumentos se construíram sob o signo da ambivalência e do pragmatismo econômico e, por conseguinte, não poderia apresentar hoje resultados mais consistentes e eficazes do ponto de vista socioambiental, comenta Lima (2011). 


\section{SISTEMAS DE GESTÃO AMBIENTAL}

A Gestão Ambiental vem ganhando um espaço crescente no meio empresarial. O aumento da consciência ecológica se faz visível em diferentes níveis e setores da sociedade, englobando empresas distintas e instituições de ensino. A Gestão ambiental envolve planejamento, organização, e orienta a empresa a alcançar metas ambientais especificas. Um aspecto relevante da gestão ambiental é que sua introdução requer decisões nos níveis mais elevados da administração e, portanto, envia uma clara mensagem à organização de que se trata de um compromisso corporativo (ALCÂNTARA et al., 2012).

A tendência atual nas empresas é que façam do seu desempenho ambiental um fator diferencial no mercado, o que significa adotar requisitos internos até, em alguns casos, mais restritivos que os legalmente impostos no País. Postura que é condizente com as exigências atuais de mercado, especialmente às empresas exportadoras.

Um Sistema de Gestão Ambiental (SGA) fornece a ordem e a consistência necessária para uma organização trabalhar suas preocupações ambientais, através da alocação de recursos, atribuição de responsabilidade, e avaliação contínua de suas práticas, procedimentos e processos.

Atualmente, as empresas utilizam instrumentos de gestão para o controle e prevenção de problemas ambientais, tais como as normas ISO 14001 e ISO 14004 relativas ao Sistema de Gestão Ambiental (SGA).

A incorporação da variável ambiental é o novo passo no ajuste competitivo das empresas, face às imposições da globalização econômica. Etapa que estabelece conexões com o acelerado processo de certificação de empresas brasileiras pela ISO série 9000 , implementadora dos sistemas de gestão da qualidade.

De fato, o Sistema de Gestão Ambiental guarda certas similaridades com sistemas de Gestão de Qualidade. Ambas as séries de normas fornecem e estabelecem um padrão de sistema de gestão que visa à melhoria do processo produtivo em empresa de qualquer porte e ramo de atividade e à demonstração, ao mercado, de sua qualificação, mediante certificação. Face às semelhanças na implementação das duas normas, é possível tirar algumas lições da ISO série 9000 aplicáveis a série 14.000. Assim, para obter a qualidade 
do processo produtivo e do meio ambiente é necessário que a empresa passe por um processo evolutivo contínuo envolvendo a avaliação, implementação, controle e revisão.

Um Sistema de Gestão da Qualidade fundamentado, por exemplo, na norma ISO 9000, é designado para estabelecer critérios de bom gerenciamento da qualidade dentro de um contexto tipicamente contratual entre a organização que o adota e o mercado cliente, como forma de contribuir com a competitividade da organização. Um Sistema de Gestão Ambiental passa a existir como consequência do reconhecimento por parte da organização da necessidade de controlar e melhorar o seu desempenho ambiental, entendido como a sua habilidade de gerenciar efeitos ambientais, como forma de, sob um prisma reativo e dependente, conseguir dentre outros, reduzir custos, atender a legislações e regulamentos evitar penalidades e/ou obter diferencial de marketing e/ou sob um prisma pró-ativo e independente, conseguir, dentre outros, desenvolver e manter os seus negócios de forma sustentável e contribuir com a preservação, conservação e/ou recuperação de fontes de recursos naturais e nichos ecológicos estratégicos (KEINERT, 2000).

\section{CONCLUSÃO}

É indiscutível que houve avanços institucionais e legais, mas estes são ainda insuficientes para instituir no Brasil um modelo sustentável de desenvolvimento, com aspectos de distribuição em que viabiliza a equidade dos benefícios materiais e sociais oriundos do crescimento econômico. Com relação à doutrina ambiental brasileira, mesmo sendo a mais bem idealizada do mundo, ainda se observa a carência de vontade política para aplicá-la, além de normas mais coerentes com a capacidade de fiscalização que, aliás, são quase que nulas diante de Leis tão complexas e contraditórias. Concordando aqui com Lima (2011), talvez os maiores obstáculos para construção de uma gestão ambiental democrática sejam os saberes reducionistas, os imperativos hegemônicos do mercado, o conservadorismo dinâmico que pretende que tudo permaneça como e onde está. 


\section{AGRADECIMENTOS}

Ao Núcleo de Estudos em Pesquisa e Planejamento Ambiental (NEPPA) da Universidade Federal de Lavras (UFLA) pelo apoio técnico-científico e ao CNPq, FAPEMIG e CAPES pelo apoio financeiro.

\section{REFERÊNCIAS}

ALCÂNTARA, L. A.; SILVA, M. C. A.; NISHIJIMA, T. Educação ambiental e os sistemas de gestão ambiental no desafio do desenvolvimento sustentável. Revista Eletrônica em Gestão, Educação e Tecnologia Ambiental, v.5, n.5, p.734-740, 2012.

BOEIRA, S. L. Política \& Gestão Ambiental no Brasil: da Rio-92 ao Estatuto da Cidade. Revista Alcance, v.10, n.3, p.525-558, 2003.

CUNHA, L. H.; COELHO, M. C. Política e gestão ambiental. In: CUNHA, S.; GUERRA, A. J. A questão ambiental: diferentes abordagens. Rio de Janeiro: Bertrand Brasil, 2008.

LAYRARGUES, P. P. Sociedade e Meio Ambiente. São Paulo: Cortez, 2000.

LIMA, G. F. da C. A institucionalização das políticas e da gestão ambiental no Brasil: avanços, obstáculos e contradições. Desenvolvimento e Meio Ambiente, n.23, p.121132, 2011.

NOGUEIRA, M. G. Ambiente e desenvolvimento sustentável: reflexão sobre a educação ambiental no âmbito da gestão ambiental empresarial. AMBIENTE \& EDUCAÇÃO, v.14, n.1, p.137-158, 2009.

MOTTA. R.S. DESAFIOS AMBIENTAIS DA ECONOMIA BRASILEIRA. Instituto de Pesquisa Econômica e Aplicada. IPEA 1998.

QUINTAS, J. S. GUALDA, N. J. A Formação do educador Para Atuar no Processo de Gestão Ambiental. Brasília: IBAMA, 1995. 
QUINTAS J. S. Introdução à gestão ambiental pública. Brasília: IBAMA, 2006.

KEINERT, T. A. Administração Pública no Brasil: Crises e Mudança de Paradigmas. São Paulo: Annablume e FAPESP, 2000.

VIANNA, M. D. B.; VERONESE, G. Políticas ambientais empresariais. Revista de Administração Pública. Rio de Janeiro, v.26, n.1, p.123-144, 1992. 